\title{
MODEL PERADILAN NON NEGARA (NON-STATE JUSTICE) SEBAGAI ALTERNATIF PENYELESAIAN SENGKETA TANAH DI KABUPATEN PAMEKASAN
}

\author{
Oleh: \\ Rina Yulianti, Sri Maharani MTVM, Nurus Zaman \\ Fakultas Hukum Universitas Trunojoyo Madura \\ E-mail : guruhfebra@yahoo.com
}

\begin{abstract}
Dispute resolution has been formally institutionalized through the courts, but not all the people in Pamekasan can access easily judiciary. In Rural Society priority harmony as the basis for solving their problems, because these mechanisms more cheap, simple, accordance with their customs and culture but this mechanism not legitimated. Socio-Legal Research methods used to explore and examine the potential mechanisms of informal dispute based on customs in Pamekasan, through in-depth interviews and secondary data collection obtained typology of dispute / disputes land based sources of conflict and Mapping Reformers. Statute Approach and case approach was to construct a new building for the legitimacy of nonstate mechanisms (Non-State Justice) which dominates land disputes models in Pamekasan. Results of this study, Pamekasan society resistant to the land disputes culture involving figures outside the formal mechanisms. There are three options land disputes models in Pamekasan by using actor resolver likes kalebun/Village Head, "Kyai" and Judge of Court. This proves the existence of pluralistic legal system in Indonesia. Regional Autonomy Act number 32 of 2004 and Act No. 30 of 1999 on Arbitration and Alternative Dispute Resolution provides an opportunity to build a judicial function at the village and to be access for justice to society and legitimated based on local wisdom.
\end{abstract}

Key Words : Alternative, Dispute Resolution, Land Dispute

\begin{abstract}
Abstrak
Penelitian ini bertujuan untuk mengetahui model proses penyelesaian di luar pengadilan atau dalam bentuk peradilan non-negara (non-State Justice) sebagai Alternatif Penyelesaian Sengketa Tanah di Kabupaten Pamekasan. Peneltian ini menggunakan metode sosio legal research. Pengumpulan data melalui wawancara mendalam dan pengumpulan data sekunder. Pendekatan perundang-undangan (statute approach) dan pendekatan kasus (case approach) dilakukan untuk mengkonstruksi bangunan baru bagi legitimasi mekanisme non negara (Non-State Justice) yang mendominasi pola-pola penyelesaian sengketa tanah di Kabupaten Pamekasan. Analisis dilakukan dengan menafsirkan data yang diperoleh secara induksi dan membandingkan, menguji atau memverifikasi dengan teori yang sudah ada. Pembandingan atau pengujian ini dimaksudkan untuk mengkaitkan temuan dengan teori yang mengkaji hal-hal yang menjadi fokus penelitian. Hasil penelitian menunjukkan bahwa masyarakat di Kabupaten Pamekasan resisten dengan budaya penyelesaian sengketa tanah yang melibatkan tokoh-tokoh diluar mekanisme formal. Terdapat tiga pilihan pola penyelesaian di Kabupaten Pamekasan untuk menyelesaikan sengketa tanah yaitu dengan menggunakan aktor penyelesai Kalebun/Kepala Desa, Kyai dan Hakim di Pengadilan. Hal ini membuktikan adanya pluralistis sistem hukum yang berlaku di Indonesia. Undang-Undang Pemerintahan Daerah nomor 32 Tahun 2004 serta Undang-undang Nomor 30 Tahun 1999 tentang Arbitrase dan Alternatif Penyelesaian Sengketa memberikan peluang untuk membangun fungsi yudisial di tingkat desa sebagai upaya untuk mendekatkan akses keadilan terhadap masyarakat dan melegitimasi berbagai pola penyelesaian yang berbasis pada kearifan lokal.
\end{abstract}

Keywords : Alternatif, Penyelesaian Sengketa, Sengketa

\section{A. Pendahuluan}

Persoalan mengenai tanah di Kabupaten Pamekasan pada kurun waktu 2011 sampai 2012 semakin hari semakin menumpuk, perseteruan ini terjadi antara pemerintah dan warga, warga dan warga, warga dan perusahaan, bahkan Ketua Komisi A DPRD Kabupaten Pamekasan, M. Suli Faris merasakan dampak menumpuknya sengketa tanah yang tidak berujung usai, mengganggu juga kinerja dewan, karena menurutnya mereka tidak bekerja hanya untuk mengurusi sengketa tanah. Sepanjang 2011 saja diawali dengan sengketa lahan sekolah, lahan puskesmas, dan lahan kuburan, dan terbaru dengan sengketa lahan garam. (Jawa Pos/ Radar Madura/2011).

Model Peradilan Non Negara... 
Pada hakikatnya, kasus pertanahan merupakan benturan kepentingan (conflict of interest) di bidang pertanahan antara siapa dan siapa, sebagai contoh konkret antara perorangan dan perorangan; perorangan dan badan hukum; badan hukum dan badan hukum, dan lain sebagainya. Sehubungan hal tersebut di atas, guna kepastian hukum yang diamanatkan UUPA (Undang-Undang Peraturan dasar Pokok Agraria), maka terhadap kasus pertanahan dimaksud antara lain dapat diberikan respons/reaksi/penyelesaian kepada yang berkepentingan (masyarakat dan pemerintah). Selama ini mekanisme penyelesaian sengketa ini dilembagakan secara formal melalui lembaga peradilan. Persoalan yang timbul dalam situasi ini, pertama, tidak semua masyarakat dapat mengakses dengan mudah lembaga peradilan formal terutama bagi masyarakat miskin dan tradisional di daerah-daerah, kedua, sifat kerukunan pada masyarakat pedesaan terutama masyarakat miskin dapat dijadikan sebagai alternatif model penyelesaian yang bertujuan untuk mengembalikan harmonisasi pada keadaaan semula.

Berdasarkan hal tersebut permasalahan penelitian ini ialah bagaimana model proses penyelesaian di luar pengadilan atau dalam bentuk peradilan non-negara (Non-State Justice) sebagai Alternatif Penyelesaian Sengketa Tanah di Kabupaten Pamekasan

\section{B. Metode penelitian}

Penelitian ini merupakan penelitian hukum empiris atau non doktrina, atau disebut juga penelitian hukum sosiologis (sosio legal research) yang menitikberatkan bekerjanya hukum di masyarakat. (Sunggono,2002;43). Pendekatan yang digunakan dalam penelitian ini adalah pendekatan perundang-undangan (statute approarch), pendekatan kasus (case approarch), dan pendekatan konseptual (conceptual approach). Pendekatan perundang-undangan dijadikan sebagai dasar analisis yang akan dilakukan terhadap implementasi pasal-pasal dalam Undang-Undang, yang berkaitan dengan peradilan non-negara atau penyelesaian sengketa informal, sedangkan pendekatan kasus dimaksudkan untuk mengidentifikasi permasalahan yang timbul serta menganalisisnya. Pendekatan konseptual digunakan untuk melakukan konstruksi mekanisme penyelesaian sengketa tanah melalui peradilan nonnegara.

Penelitian ini dilaksanakan di Wilayah Kabupaten Pamekasan serta kegiatan analisis di laboratorium Hukum Fakultas Hukum Universitas Trunojoyo.
Cara memperoleh data primer dengan mengunakan teknik wawancara mendalam (in dept interview). Informan kunci yang menjadi sumber data primer dalam penelitian ini adalah yang mereka yang berkaitan langsung sebagai pihak-pihak yang terlibat dalam penyelesaian sengketa tanah, antara lain :

a. Pihak-Pihak yang berselisih/bersengketa

b. Tokoh Formal, pihak-pihak yang masuk dalam struktur organisasi pemerintahan, mulai dari tingkat Desa sampai dengan tingkat Kabupaten, termasuk juga di dalamnya aparat penegak hukum.

c. Tokoh Informal, adalah pihak-pihak yang mempunyai pengaruh besar terhadap masyarakat di Kabupaten Pamekasan yang biasanya juga menjadi sesepuh atau yang ditokohkan.

Sumber data sekunder diperoleh dari kantorkantor pemerintahan, mulai dari tingkat desa sampai kabupaten dan juga kantor-kantor penegak hukum.

Data kualitatif yang diperoleh selama penelitian tersebut, kemudian ditambah pernyataanpernyataan para informan (interpretasi emik) dijadikan sebagai dasar menyusun deskripsi menurut persepsi peneliti (interpretasi etik) yang menyangkut berbagai hal guna mendukung proses konstruksi mekanisme alternative penyelesaian sengketa tanah di luar pengadilan atau dalam forum peradilan non-negara.

Analisis berikutnya dilakukan dengan menafsirkan data yang diperoleh secara induksi dan membandingkan, menguji atau memverifikasi dengan teori yang sudah ada. Pembandingan atau pengujian ini dimaksudkan untuk mengkaitkan temuan dengan teori yang mengkaji hal-hal yang menjadi fokus penelitian.

\section{Simpulan}

Tipologi kasus tanah yang muncul di pamekasan melibatkan antara warga dan warga, warga dan penguasa, warga dan badan hukum baik publik maupun privat. Model penyelesaian sengketa tanah di wilayah Kabupaten Pamekasan sebagian besar menggunakan mekanisme di luar mekanisme negara/peradilan formal hal ini di buktikan dengan tingginya kepercayaan mereka terhadap tokoh Kalebun (Kepala Desa) dan tokoh Kyai. Meskipun banyak sengketa tanah di Kabupaten Pamekasan dilakukan dengan model di luar pengadilan tetapi antara daerah yang satu dan yang lain mempunyai perbedaan dalam memilih atau menentukan tokoh atau mediator. 


\section{DAFTAR PUSTAKA}

Abdullah, Abdul Gani, 2007, "Merekonstruksi Sistem Hukum dan Hubungan Pusat dan Daerah", JurnalVaria Peradilan, Tahun ke XXII No. 265, Desember.

A.B. Wiranata, I Gede, 2005, "Hukum Adat Indonesia Perkembangannya dari Masa ke Masa", Citra Aditya Bakti.

Abdurrasyid, Priyatna , 1996," Penyelesaian Sengketa Perdagangan Internasional di Luar Pengadilan", makalah, Seminar Nasional Hukum Bisnis, FH, UKSW, Semarang.

Connolly, B. (2005) 'Non-State Justice Systems and the State: Proposals for a Recognition Typology', 38 Connecticut Law Review 239, dalam laporan hasil Tim Justice For The Poor Program at The World Bank Indonesia tahun 2009.

Emerzon, Joni, 2000, "Alternatif Penyelesaian Sengketa di Luar Pengadilan", Gramedia Pustaka Utama, Jakarta.

Goodpaster, Gary, 1993, "Negosiasi dan Mediasi : Sebuah Pedoman Negosiasi dan Penyelesaian Sengketa Melalui Negosiasi", Elips Project, Jakarta.

Justice for The Poor Program at The World Bank Indonesia, 2009, Menemukan Titik Keseimbangan Mempertimbangakan Keadilan Non-Negara di Indonesia;

Mahmud Marzuki, Peter 2005, "Penelitian Hukum", Prenada Media, Jakarta.

M. Nolan-Haley, Jacqueline, 1991, "Alternatif Dispute Resolution", West Publishing Company. Nurjaya, I Nyoman 2006, "Pengelolaan Sumber Daya Alam Dalam Perspektif

Antropologi Hukum", Program Pasca Sarjana Universitas Brawijaya dengan Universitas Negeri Malang. Purba, Rehngena, 2001. "Pilihan Penyelesaian Sengketa di Luar Pengadilan (Studi Kasus Fungsi Lembaga Runggun Adat pada Masyarakat Karo di Kabupaten Karo) ", Jurnal Fakultas Hukum UNAIR -Yuridika, Vol. 12, No. 3.

Rasjidi, Lili dan I.B. Wiyasa Putra, 1993. "Hukum sebagai suatu system", Remaja Rosdakarya, Bandung. Widjaja, HAW, 2003. "Otonomi Desa Merupakan Otonomi Yang Asli, Bulat dan Utuh", Raja Grafindo Persada, Jakarta.

Witanto, Darmoko Yuti, 2008, "Hukum Adat Laut Sabang, Kearifan-Kearifan yang Terlupakan", Kompas, Jakarta.

Yulianti, Rina DKK, 2009,"Laporan Hasil Penelitian Rekonseptualisasi Fungsi Lembaga Adat Sebagai Pilihan Peneyelesaian Sengketa di Luar Pengadilan di Wilayah Pulau Terpencil Studi kasus Kabupaten Sumenep), DP2M-DIKTI.

Radar Madura Berita Daerah Pamekasan, tanggal cetak 9April 2010, "Di 2010 Sengketa Tanah Dominan",Jawa Pos Group.

Undang-Undang Dasar1945

Undang-Undang Nomor 30 Tahun 1999 LNRI Tahun 1999 Nomor 138 tentang Arbitrase dan Alternatif Penyelesaian Sengketa

Undang-Undang Nomor 10 Tahun 2004 tentang Pembentukan Peraturan perundang-Undangan.

Undang-Undang Nomor 32 Tahun 2004 LNRI Tahun 2004 Nomor 125 tentang Pemerintahan Daerah Peraturan Pemerintah Nomor 72 Tahun 2005 tentang Desa 